\title{
An Aeromycological Study of Pathogenic Fungi Prevalent in the Neonatal Intensive Care Unit of J.L.N. Hospital, Ajmer (Raj.)
}

\author{
Parul Chaturvedi ${ }^{1 *}$, Vijaylatha Rastogi ${ }^{1}$, Abhila Parashar ${ }^{1}, \operatorname{Pushpanjali~Verma~}^{1}$, \\ Shruti Sharma ${ }^{2}$ and B.S. Karnawat ${ }^{2}$
}

${ }^{1}$ Department of Microbiology, Jawaharlal Nehru Medical College \& Associated group of Hospitals, Ajmer (Raj.), India

${ }^{2}$ Department of Pediatrics, Jawaharlal Nehru Medical College \& Associated group of Hospitals, Ajmer (Raj.), India

*Corresponding author

\begin{tabular}{|c|}
\hline Keywords \\
\hline $\begin{array}{l}\text { Aspergillus flavus, } \\
\text { Air samples, } \\
\text { Aeromycology, } \\
\text { Nosocomial fungal } \\
\text { infection }\end{array}$ \\
\hline Article Info \\
\hline $\begin{array}{l}\text { Accepted: } \\
15 \text { May } 2019 \\
\text { Available Online: } \\
\text { 10 June } 2019\end{array}$ \\
\hline
\end{tabular}

\section{Introduction}

Nosocomial Infections (NI) are a serious medical problem, particularly in intensive care units. NI comprise 25 per cent of the total number of infections occurring in

\section{A B S T R A C T}

Nosocomial fungal infections in neonatal intensive care units are a serious emerging problem. However, the role of fungal bio-aerosols as the source of such infections has not been explored in the NICU setting. Hence, this study was done to know the fungal composition of aerosols in NICU as the source of neonatal nosocomial infections. $1 \mathrm{~m}^{3}$ of NICU air was sampled fortnightly over 12 months onto SDA with chloramphenicol using a sieve type air sampler. AC filter dust and clinical samples (in BHI broth) from neonates developing signs and symptoms of infection $48 \mathrm{hrs}$ after admission to NICU were also taken. Inoculated media were incubated at $25^{\circ}$ and $37^{\circ} \mathrm{C}$ for upto 3 weeks \& on growth, colony count per $\mathrm{m}^{3}$ of air was estimated. Fungi grown on SDA plate were identified by standard conventional techniques. $81 \%$ of air samples yielded mixed growth with predominance of Aspergillus flavus and Aspergillus niger (66.6\%) while 19\% yielded pure isolates with predominance of Rhizopus rhizopodiformis $(9.5 \%)$. AC filter dust, yielded mixed growth of flavus and niger (61\%), pure growth of Aspergillus niger $(33.3 \%)$ and Aspergillus flavus (4.7\%). Incidence of nosocomial fungal infection was 8.09 per thousand per yr. In $6 \%$ cases, fungal bio-aerosols are suspected to be the source with case fatality rate of $83.3 \%$. This study highlights the role of Aspergillus spp. in bio-aerosols of NICU as the potential source of nosocomial infection leading to early high mortality in neonates. Continuous monitoring and surveillance of fungal bio-aerosols as source of nosocomial infections in NICU air need to be done over a long period of time to institute suitable 
per 1000 patient days, the rate varies from $4.8^{18}$ to $22 .^{[6,20]}$ Neonates have unique susceptibilities, their immunologic immaturity and the closed setting of the Neonatal ICU (NICU) set the state for development of nosocomial infections. The rate of nosocomial fungal infections in neonates worldwideis 12$15 \%$ while in India it is $6-8 \%{ }^{[25]}$. A high correlation is reported between the prevalence of infection and the duration of hospitalization. Fungi are a serious threat to public health and are part and parcel of soil and the environment, especially atmospheric air, which acts as the most common source of opportunistic as well as true fungal infections $^{14}$..In the past, fungi were considered to be merely non-pathogenic or simply laboratory contaminants But due to circumstantial immunocompromised background among the patients, these very non-pathogenic and contaminant fungi have now proved to be significant pathogens and are encountered as emerging agents of life threatening fungal diseases. A dramatic increase in the prevalence of fungal infections has been observed in the recent years ${ }^{[5]}$ Invasive Fungal Diseases (IFDs) are devastating opportunistic infections that result in significant morbidity and death in a broad range of paediatric patients, particularly those with a compromised immune system. Recognizing them can be difficult, because nonspecific clinical signs and symptoms or isolated fever are frequently the only presenting features. Therefore, a high index of clinical suspicion is necessary in patients at increased risk of IFD.

Although much has been talked about the various sources of nosocomial transmission in neonates including health care worker cross transmission or infected iv sets and catheter transmission but very less has been known about the effect of airborne source and transmission of nosocomial fungal infection in these babies. In our NICU overall sepsis rate and rate of fungal sepsis are 200-230 per 1000 and 5-140 per 1000 NICU admissions respectively. Off and on outbreaks do occur due to failure of stringent infection control practices. Fungal outbreaks are also common. However, establishing fungal etiology is difficult as it is also least suspected and hence antifungal treatment are usually very delayed or seldom usually attempted. So, this study was basically aimed at determining composition of fungi in air of NICU and identifying their probable role in neonatal infections in NICU. This led to a better understanding and control of aerobic transmission of fungal infections in NICU\& thus help in reducing infection rate.

\section{Materials and Methods}

The present study was carried out at the Neonatal Intensive Care Unit (NICU) and Department of Microbiology of J.L.N Hospital, Ajmer from July 2016 to Sept. 2017over a period of 12 months. It was an observational prospective ecological study. Over a period of 12 months 2437 neonates were admitted in the NICU out of which 846 clinically relevant samples were sent to Microbiology laboratory. Only 135 neonates out of these who developed signs and symptoms of sepsis 48 hours after were suspected to be suffering from nosocomial infection. Since this was an ecological study to know environmental risk for neonatal fungal infections in NICU, sample size calculation was not needed. However, the sampling duration covered all the 5 seasons (viz. rainy, autumn, winters, spring, summer) in order to study seasonal trend/variation in the incidence of fungi in the NICU environment.

All the neonates developing signs and symptoms of infection 48 hours after admission to NICU i.e. Nosocomial infection were included while all neonates admitted 
with or developed signs and symptoms of infection/septicemia/abscess within 48 hours of hospitalization were excluded. Samples were collected for mycological examinations from the NICU environment air \&from the AC filter dust every fortnight during the study period and blood/CSF from neonates developing signs and symptoms of infection/ septicemia/ meningitis 48 hours after admission to NICU.

Samples of NICU neonates received in Department of Microbiology for culture and sensitivity were also followed for fungal isolates and included in the study. The volumetric method of air sampling was used in this study using air Petri plating system which is based upon the principle of sieve impact or which aspirates air through a perforated plate. The air to be sampled was drawn through a perforated head using a sieve type air sampler (Hi-Media India, model noLA881) at the rate of $100 \mathrm{~L} / \mathrm{min}$ for $10 \mathrm{~min}$. The inflowing air impacted on the surface of SDA with chloramphenicol $90 \mathrm{~mm}$ Petri dish to enable fungal growth \&was incubated at $25^{\circ} \mathrm{C}$ in the incubator for upto 3 wks at the end of the sampling period. After incubation it was possible to count the $\mathrm{CFU} / \mathrm{cm}^{3}$ (Colony Forming Units $/ \mathrm{cm}$ ) and evaluate the air biocontamination level of the critical area on the basis of air volume sampled. Any growth of fungi on the plate was noted and colony counts per cubic metre of air calculated (as given below) and were identified after sub on fresh SDA plates. Also incubation of subcultures at $37^{\circ} \mathrm{C}$ was done to rule out/ identify dimorphic fungi. Calculation of fungal colony count was done using formula: fungal colony count $=$ Number of fungal colonies on SDA plate at the end of 3 days and finally at 21 days (if countable)/Total volume of air sampled in $\mathrm{m}^{3} * 1 \mathrm{~m}^{3}$.

Since $1000 \mathrm{~L}\left(1 \mathrm{~m}^{3}\right)$ of air was sampled every time, number of colonies growing on plate directly gave the colony count. Any fungus grown on SDA plate was followed and identified by standard conventional techniques, viz-Rate of growth at $22^{\circ} \mathrm{C}$ and $37^{0} \mathrm{C}$ and Colony morphology. Neonatal samples were collected \&inoculated in BHI broth at $37^{\circ} \mathrm{C}$. The broth if found turbid was subcultured on SDA and followed for further identification.

SDA with chloramphenicol is a selective medium required for isolation of pathogenic fungi and excellent basal medium to which addition of antibiotic such as chloramphenicol acts as inhibitory substance for bacteria and promotes selective cultivation of various fungal pathogens. For Yeasts, gram's stain, germ tube, urease test, corn meal agar morphology and VITEK-2C automated identification was done and formoulds, LPCB micromorphology (Lactophenol Cotton Blue teased mount), scotch tape preparation and slide culture micromorphology on PDA was used to study morphological features of fungal isolates after the strain grew on culture medium.

The LPCB mount serves as best method to study morphological details of fungal isolates in which fungal hyphae, conidia, vesicle, metulae, rhizoids can be very well appreciated, while Scotch tape preparation is a bench test used to observe fungi in a fashion similar to their "native" conformation in culture. In Slide cultures micromorphology on PDA is used to study undisturbed morphological details of fungi, indicated when teased mount of LCB is inconclusive in particular fungal isolate. Antifungal susceptibility testing was proposed to be done only on those fungal isolates obtained both from neonates and environment that are identical phenotypically by Disc diffusion method. However, since the isolates obtained from aeromycology sampling and from neonatal blood samples which were found to 
be identical phenotypically were all moulds for which we did not have proper facilities available for performing antifungalsusceptibility testing at our institute

\section{Results and Discussion}

Total 21 aeromycology samples were collected from the NICU environment air of which 17 samples (81\%) yielded growth with mixed growth of $A$. flavus and A. niger (66.6\%). While, 4 samples out of 21 (19\%) yielded pure isolates comprising of Rhizopus rhizopodiformis (9.5\%), Alternaria (4.7\%) and Absidia species (4.7\%). Maximum fungal load of A.flavus was observed in the summer months (March- June) and the rainy season (September-October) of the year with few occasional peaks in winters. (November) (Fig. 1). Persistently high fungal load of A.niger was observed during the dry months of the year i.e Summers (March -June), few peaks with an overall low fungal colony count were observed during other seasons (Fig. 2).

Total 23 samples were collected throughout the year (during the period while A.C was functional) with predominant mixed growth of A. flavus and A. niger (61\%), followed by pure growth of A. niger (33.3\%) and A. flavus (4.7\%) (Fig. 3).

Total 846 neonatal blood samples were received from the NICU for blood culture sensitivity out of which 561(66.3\%) samples were found positive for microbial growth. On the basis of evaluation of the presenting complaints and clinical status of the patient within 48 hours of admission, 135(24.1\%) positive blood samples turned out to be nosocomial septicemia cases. On further processing of the blood cultures of these suspected nosocomial cases, 19 (14\%) patients grew fungi ( 8 moulds and 11 yeasts.) and 116 samples grew bacteria. Since, this study aims to find out the incidence of nosocomial fungal infection in NICU neonates and we did not recover any yeast from our aeromycology samples, so only those 8 samples growing moulds were followed for further identification and they showed phenotypic resemblance with the moulds isolated from NICU air and A.C. filter dust $\{$ Rest 11 samples which grew yeast were identified to be of candida species, for which further processing was beyond the scope of our study\}. 5 out of 8 confirmed nosocomial fungal septicemia cases succumbed to the infection while 3 of them left against medical advice (Table 1).

The mean fungal load throughout the year in NICU came out to be $99.25 \mathrm{cfu} / \mathrm{m}^{3}$ with maximal fungal load in the summers and rainy season and less in winters. Comparing, the difference in mean fungal load of NICU environment during the two major seasons of the year; summers and winters, the mean fungal load in summer was $148.75 \mathrm{cfu} / \mathrm{m}^{3}\left(\overline{\mathrm{x}}_{1}\right)$ while in winters its was 92.5 $\mathrm{cfu} / \mathrm{m}^{3}$ (Table 2 and Fig. 4).

Using the formula for standard deviation, the standard deviation \&th standard error of difference between the means, the actual difference between the two means (148.7556.25) came out to be $>2$ Standard error of difference between the two means. Hence, the difference in the mean fungal load of summer and winters was statistically significant. Further, in this study the incidence of nosocomial fungal septicemia is 8.09 per thousand per year. Out of the 19 fungal cases reported, in $8(6 \%)$ fungal bio-aerosols are suspected to be the source with a case fatality rate of $83.3 \%$. The correlation in the environmental isolates and clinical isolates was further confirmed by MALDITOFF BIOTYPING. The disease specific mortality rate due to nosocomial fungal septicemia attributed to fungal bio-aerosols in my study came out to be $1.2 \%$. 


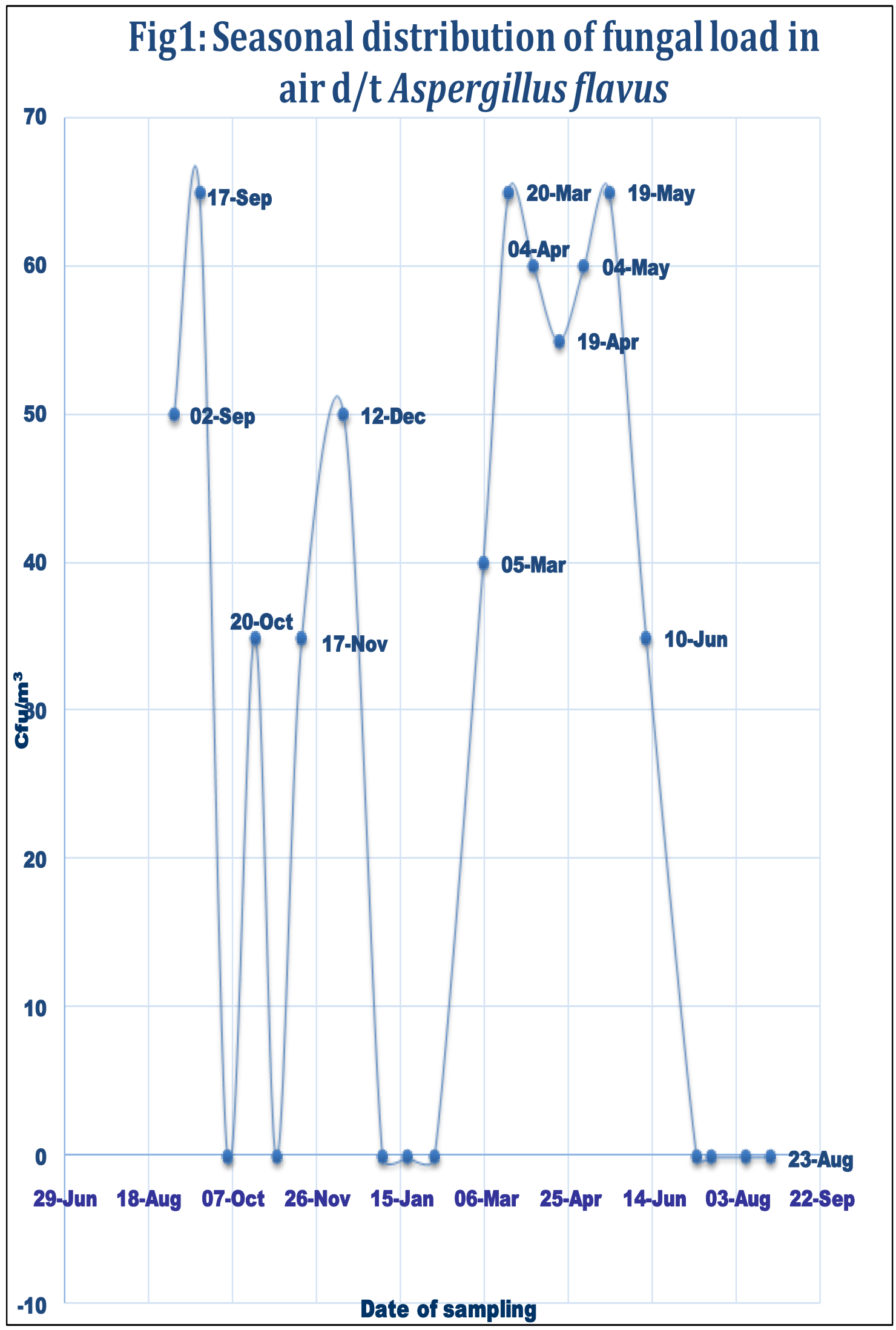




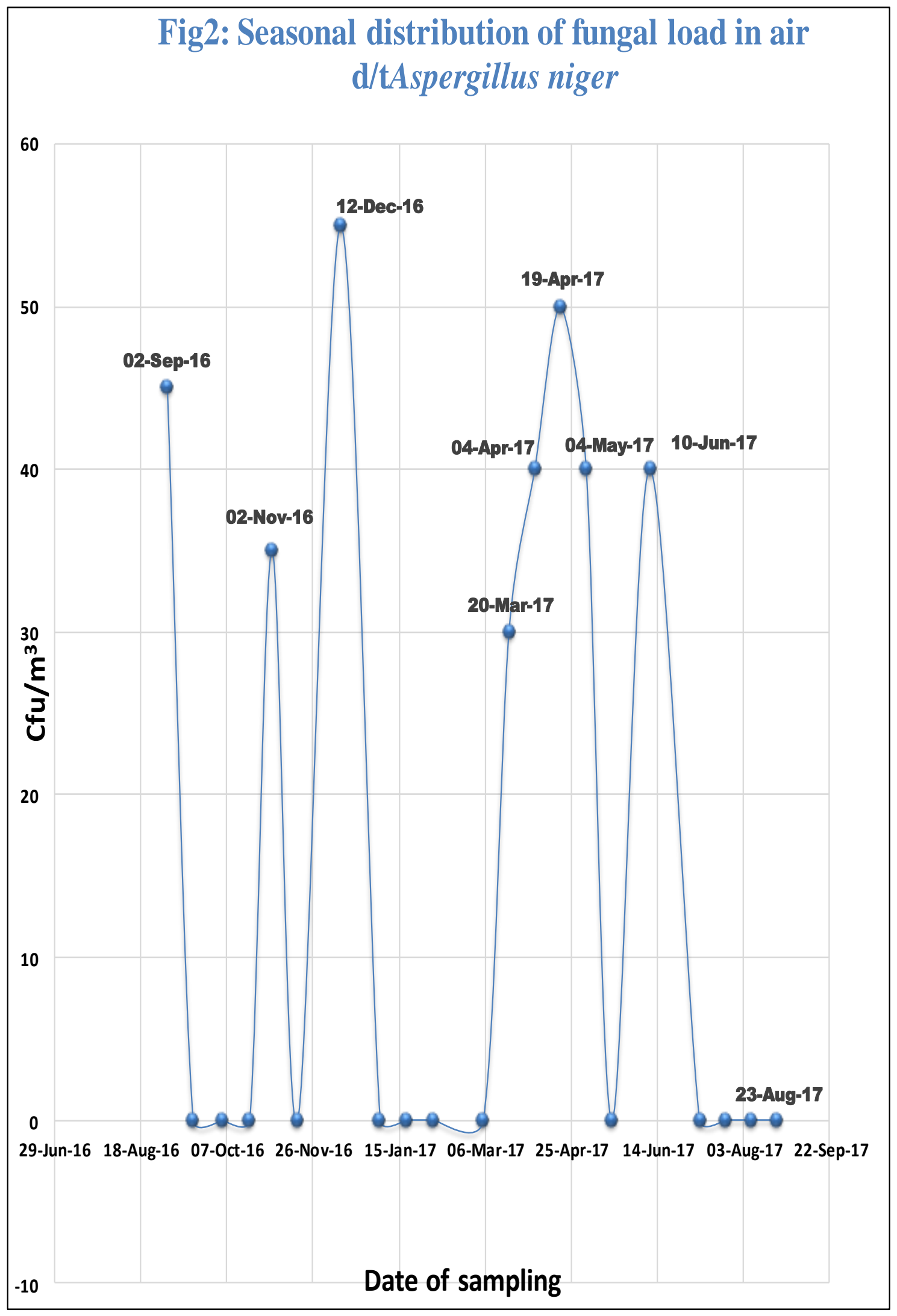


Fig3: Prevalence of fungi in A.C. filter dust

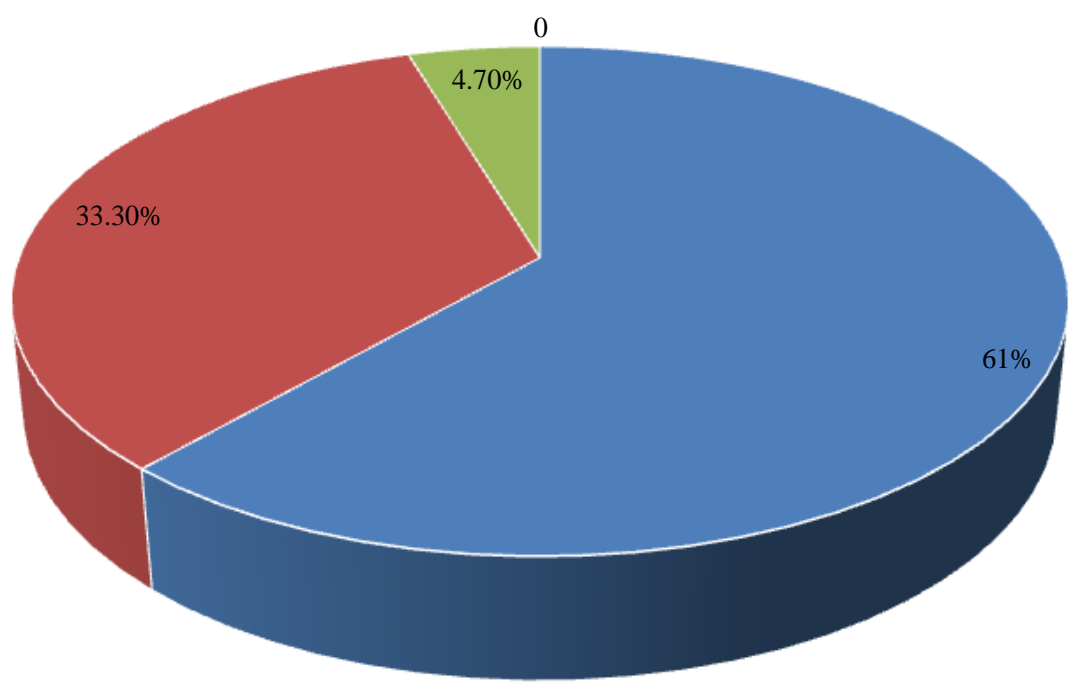

\section{Fig: 4 Overall fungal load throughout the year in NICU enviromment}

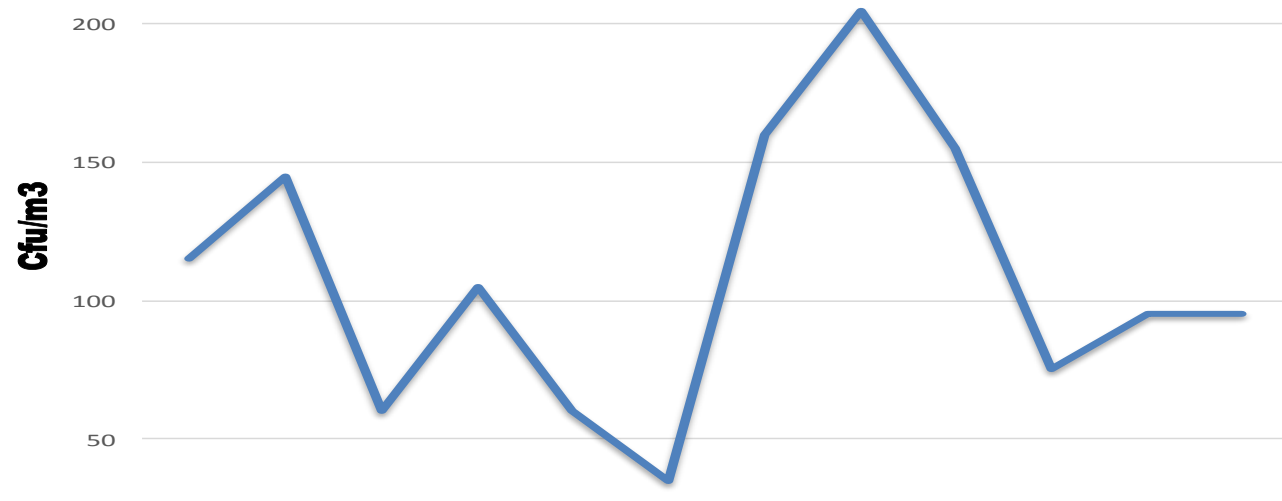

o

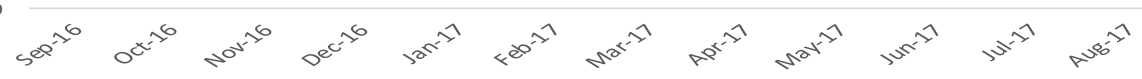
MONTHS 
Table.1 Fungi isolated from neonatal blood samples from NICU which showed phenotypic resemblance with the aeromycology samples

\begin{tabular}{|c|c|c|c|}
\hline $\begin{array}{l}\text { Date of } \\
\text { detection }\end{array}$ & Baby name & $\begin{array}{l}\text { Fungi isolated } \\
\text { From neonates }\end{array}$ & $\begin{array}{l}\text { Fungi isolated in that period from } \\
\text { NICU air }\end{array}$ \\
\hline $17 / 10 / 16$ & B/O Manju & A.niger\&A.flavus & \multirow{3}{*}{$\begin{array}{l}* \text { *. niger and A. flavus(A.C.)-4 } \\
\text { \& } 20 \text { Oct/2016 } \\
\text { *R.rhizopodiformis(air)- } 4 \text { Oct/2016 } \\
\text { *A.flavus \&A.niger(air)- } \\
20 \text { Oct/2016 }\end{array}$} \\
\hline $22 / 10 / 16$ & B/o Jagwati & A.niger\&A. fumigatus & \\
\hline $25 / 10 / 16$ & B/o Kali & A.fumigatus & \\
\hline $12 / 11 / 2016$ & B/o Pinki & A.terreus,A.fumigatus & $\begin{array}{l}\text { *A.fumigatus \& A. niger } \\
\text { (air) }-2 \text { Nov/2016 } \\
* \text { Fusarium sp. \&A.flavus } \\
\text { (air) }-17 \text { Nov/2016 }\end{array}$ \\
\hline $18 / 03 / 2017$ & B/o Teeji & A. fumigatus & \multirow{3}{*}{$\begin{array}{l}\text { *A.flavus\&A.fumigatus(air) } \\
\text {-5Mar/2017 } \\
\text { *A.flavus\&A.niger-(air) } \\
20 \text { Mar/2017 }\end{array}$} \\
\hline 22/03/2017 & $\begin{array}{ll}\text { B/o } & \text { Devi } \\
\text { Prakash } & \end{array}$ & A.flavus & \\
\hline 28/03/2017 & B/o Unknown & A.flavus & \\
\hline 11/04/2017 & B/oShabana & A.flavus & $\begin{array}{l}\text { *A.niger\&A.flavus-(air) } \\
4 \text { Apr/2017 } \\
\text { *A.flavus\&A.niger-(air) } \\
19 \text { Apr/2017 }\end{array}$ \\
\hline $15 / 05 / 2017$ & B/o Ruksar & A. flavus & $\begin{array}{l}\text { *A.niger and A.flavus-(air) } \\
4 \text { May/2017 } \\
\text { *A.flavu } \text { \& niger (A.C)-4 } \\
\text { \&19 May/2017 } \\
\text { *Penicillium sp. and A.flavus-(air) } \\
\text { 19May/2017 }\end{array}$ \\
\hline
\end{tabular}

Table.2 Overall fungal load throughout the year in NICU environment

\begin{tabular}{|l|l|}
\hline Month & Fungal load $\left(\mathbf{c f u} / \mathbf{m}^{\mathbf{3}}\right)$ \\
\hline September & 115 \\
\hline October & 145 \\
\hline November & 60 \\
\hline December & 105 \\
\hline January & 60 \\
\hline February & 35 \\
\hline March & 160 \\
\hline April & 205 \\
\hline May & 155 \\
\hline June & 75 \\
\hline July & 95 \\
\hline Aug & 95 \\
\hline
\end{tabular}


In present study total 21 aeromycology samples were collected from the nicu environment air of which 17 samples $(81 \%)$ yielded mixed growth with predominance of A.flavus \& A. niger (66.6\%) and rest (14.28\%) were mixed growth of Rhizopus and other species viz; A.fumigatus, non-sporing hyalohyphomycetes, Penicillium and Fusarium species. While, 4 samples out of 21 (19\%) yielded pure isolates comprising of Rhizopus rhizopodiformis (9.5\%), Alternaria(4.7\%) and Absidias pecies (4.7\%). Since, no comparable studies could be found so far in literature where aeromycoflora of NICU has been studied coorelating it with the nosocomial fungal infections in neonates, this study is an initiative to add to the knowledge of existing aeromycoflora of the hospitals and its clinical implications and hence compared with data of studies on aeromycoflora of hospital in units/wards to know general prevalence in hospitals.

Findings similar to the present study were obtained by HAO Zhen-Feng et al.,(2011), in two hospitals of China in 2011 in which the most prevalent fungi collected from air and surfaces of hospital environment were Aspergillus spp. Also Penicillium spp., Cladosporium spp., Alternaria spp., Fusarium which is comparable to current study findings.In a study conducted by Nasim, G etal in 1998 in Eye and Surgical Wards of four local hospitals of Lahore (Pakistan), A.flavus was recorded in highest frequency. In overall Aspergillus, Penicillium, Alternaria\& Fusarium sp. were isolated which is similar to the findings of present study.

In the study conducted by José Manuel RíosYuil et al., in 2012, in Brazil, isolation of Aspergillus spp.(non-fumigatus), Penicillium spp., and Fusarium spp. in the air of the ICU are comparable to the current study findings. Findings similar to the current study were reported by Verma et al., (1992) where
Aspergillus sp., Curvularia sp., Alternaria sp., Cladosporium sp. were the most frequent fungal species in the allergy ward of medical college, Jabalpur. The results of the above studies differ from the results of the present study to some extent which may be due to variation in temperature, humidity, climatic and geographical conditions. Also these studies were not done in ICU. Hence, the significance of determination of local fungi microflora in NICU air.

In the present study maximum fungal load of A.flavus and A. niger was observed in the summers and the rainy season of the year and less in winters, A.fumigatus was observed for a short duration in the winters and maximum load of Rhizopus rhizopodiformis was observed in the rainy season, with off and on peaks in the early winters and spring. The mean fungal load throughout the year in NICU is $99.25 \mathrm{cfu} / \mathrm{m}^{3}$ with maximal fungal load in the summers and rainy season and less in winters.

These findings are almost similar to the findings of the study done by HAO ZhenFeng et al., in 2011 in the intensive care units of two hospitals of china who reported the air fungal load of $91.94 \mathrm{cfu} / \mathrm{m}^{3} \& 71.02 \mathrm{cfu} / \mathrm{m}^{3}$. The air fungal load was higher in summers and autumn and lower in winters.

The findings of the study done by José Manuel Ríos-Yuil et al., (2012) in a Brazilian hospital also near present study findings with the presence of mean concentration of fungi in the air of the ICU as 85.08 \pm 29.19 $\mathrm{CFU} / \mathrm{m}^{3}$.Similar to this study findings, maximum number of fungal colonies were observed in the month of May in Eye and Surgical Wards of four local hospitals in a study done at Lahore, Pakistan by Nasim et al., (1998). The slight variation observed in the findings of these studies can be attributed to the local environment and climate 
conditions and the type of ventilation in the hospital setting.

In the present study the incidence of nosocomial fungal infection is 8.09 per thousand per year. Out of the 19 fungal cases reported, in 8 (6\%) fungal bio-aerosols are suspected to be the source based on phenotypic similarity of isolates with a case fatality rate of $83.3 \%$. The disease specific mortality rate in this study came out to be 1.2\%.A.flavus, A.fumigatus and A. niger were the fungi implicated to be the cause of nosocomial fungal infection encountered in NICU neonates. Though, studies observing nosocomial fungal infections in neonates have not been reported so far but there are various studies from regions worldwide which highlight the occurrence of nosocomial fungal infections in adult patients.

So, study done by George J etal(2010)in USA reported A.fumigatus as the species most often associated with nosocomial fungal infection. Other species, including A.flavus, A.niger, A.terreus, A.nidulans were also reported. Aspergillosis turned out to be an important cause of morbidity and mortality. The most frequent nosocomial source of Aspergillus infection seemed to be contaminated air. In the study done by Scott K. etal in 1996 a dramatic rise in the percentage of all nosocomial bloodstream infections caused by fungi, from $5.4 \%$ in 1980 to $9.9 \%$ in 1990 was reported - the nosocomial fungal infections rate in the current study is $14 \%$. Study done by M M Lopes etal in 2006 in a Portuguese paediatric hospital reported the incidence of nosocomial fungal infection in the hospital as 3.0 per 1000 patients slightly less as compared to present study.

However, it was significantly higher in intensive care units than in all the other wards and services. In the study done by Rao et al., in Mumbai in 2005, the overall mortality rate for disseminated fungal infections in neonates was $50 \%$. which is less than case fatality rate reported in present study.

Higher infection rates and incidence reported in the current study can be attributed to type of ventilation, climatic conditions of the study area, levels of humidity/dampness in NICU environment, low index of suscpicion of fungal infection and therefore lesser efforts for prevention of the causes. Nevertheless the most important factor for the increased nosocomial fungal infection rates is that of immunological immaturity and high risk of neonate population studied.

In the present study, the fungi prevalent in NICU environment showed seasonal variation with overall fungal load throughout the year being higher in summers and rainy season and less in winters. A.flavus and A.niger turned out to be the predominant species with maximum occurrence in summers, followed by Rhizopus rhizopodiformis which was more evident in the rainy season of the year.

This seasonal trend can be attributed to the level of humidity and dampness in the NICU environment and the higher fungal load in a restricted and sensitive area like NICU creates a need on evaluation of the type of ventilation and the interaction of NICU environment with the outside air and the probable causes of high levels of moisture promoting fungal growth.

Further, the case fatality rate and the disease specific mortality rate due to nosocomial fungal septicemia attributed to fungal bioaerosols indicate the high chances of probable invasion of fungal spores in neonates through the NICU air and there is a need to raise the index of suspicion in fungal septicemia in neonates rather than considering it a rare, by chance occurrence.

This will probably lead to increase in timely institution of antifungal therapy and thus decrease in cases of fungal septicemia. 


\section{References}

1. Gniadek A, Macura AB- Intensive care unit environment contamination with fungi: Advances in Medical Sciences. Vol. 52, 2007pg283-287.

2. Łazińska B, Rokosz A, SawickaGrzelak A, Łuczak M. Bakteryjneigrzybiczeczynnikizakażeń u pacjentówOddziałuIntensywnejTerapii (OIT). Zakażenia, 2003; 73-4: 76-7.

3. Fleischer M. Badaniamikrobiologiczneśrodowiskaszp italnego.Zakażenia, 2003; 18-20: 22-3.

4. Kurnatowski P, Wieczorek A, Gaszyński T, Tyczkowska-SierońE. Zarażeniagrzybicze $\mathrm{u}$ pacjentówhospitalizowanychnaOddziale IntensywnejTerapii. WiadParazyt, 2005; 51: 23-7.

5. Fischer G, Dott W- Relevance of airborne fungi their secondary metabolites for environmental, occupational and indoor hygiene: Arch Microbiol, 2003; 179: 75-82.

6. M.T. Montagna, G. Lovero, O. De Giglio, R. Iatta, G. Caggiano, O. Montagna, N. Laforgia, and "Aurora" Project Group-Invasive fungal infections in Neonatal Intensive Care Units of Southern Italy: a multicentre regional active surveillance (AURORA Project): J Prev Med Hyg. 2010 Sep; 51(3):125-30.

7. Benjamin DK Jr, Stoll BJ-Infection in late preterm infants: Clin Perinatol 2006;33:871-82

8. Chapman RL.-Prevention and treatment of Candida infections in Neonates: Semin Perinatol 2007; 31: 39-46.

9. Stoll BJ, Hansen N, Fanaroff AA, et al.,-Late-onset sepsis in very low birth weight: the experience of the NICHD Neonatal Research Network. Pediatrics 2002; 110: 285-91.
10. Kaufman D, Fairchild KD - Clinical microbiology of bacterial and fungal sepsis in very-low-birth-weight infants: Clin Microbiol Rev 2004; 17: 638-80.

11. Levy I, Shalit I, Askenazi S, et al.,Duration and outcome of persistent candidaemia in newborn infants: Mycoses 2006; 49: 197-201.

12. Cotten CM, McDonald S, Stoll B, et al.,-The association of third-generation cephalosporin use and invasive candidiasis in extremely low birthweight infants: Pediatrics 2006; 118: 717-22.

13. Nicholas A. Bokulich, David A. Mills, and Mark A. Underwood- Surface Microbes in the Neonatal Intensive Care Unit: Changes with Routine Cleaning andover Time; J Clin Microbiol. 2013 Aug; 51(8): 2617-2624.

14. Khan et al., 2009- Fungal pollution of indoor environments and its management: Saudi J Biol Sci. 2012 Oct; 19(4): 405-426.Published online 2012 Jun 15.

15. Samet and Spengleretal - Indoor Environments and Health: Moving Into the 21st Century: Am J Public Health. 2003 September; 93(9): 1489-1493.

16. Craft A, Finer N - Nosocomial coagulase negative staphylococcal (CoNS) catheter-related sepsis in preterm infants: definition, diagnosis, prophylaxis, and prevention. $\mathrm{J}$ Perinatol 2001; 21: 186-192.

17. Zafar N, Wallace CM, Kieffer P, Schroeder P, Schootman M, Hamvas A. - Improving survival of vulnerable infants increases neonatal intensive care unit nosocomial infection rate: Arch Pediatr Adolesc Med 2001;155:10981104.

18. Ferguson JK, Gill A - Risk-stratified nosocomial infection surveillance in a neonatal intensive care unit: report on 
24 months of surveillance: $J$ Paediatr Child Health 1996; 32: 525-531.

19. Hentschel J, de Veer I, Gastmeier P, Ruden H, Obladen M. - Neonatal nosocomial infection surveillance: incidences by site and a cluster of necrotizing enterocolitis. Infection 1999; 27: 234238.

20. Drews MB, Ludwig AC, Leititis JU, Daschner FD. - Low birth weight and nosocomial infection of neonates in a neonatal intensive care unit.: J Hosp Infect 1995; 30: 65-72.

\section{How to cite this article:}

Parul Chaturvedi, Vijaylatha Rastogi, Abhila Parashar, Pushpanjali Verma, Shruti Sharma and Karnawat, B.S. 2019. An Aeromycological Study of Pathogenic Fungi Prevalent in the Neonatal Intensive Care Unit of J.L.N. Hospital, Ajmer (Raj.). Int.J.Curr.Microbiol.App.Sci. 8(06): 2091-2102. doi: https://doi.org/10.20546/ijcmas.2019.806.249 